\title{
REALISASI PRINSIP KESANTUNAN DALAM DISKUSI INTERNET DI TIGA GRUP DISKUSI HINDU INDONESIA
}

\author{
Wayan Pageyasa \\ Program Studi Pendidikan Bahasa dan Sastra Indonesia, \\ Fakultas Keguruan dan Ilmu Pendidikan, \\ Universitas 19 November
}

\begin{abstract}
Abstrak
Penelitian ini bertujuanuntuk memperoleh pemahaman yang mendalam tentang realisasi prinsip kesantunandalam diskusi internet di tiga grup diskusi Hindu Indonesia. Realisasi prinsip kesantunan tersebut terdiri atas pematuhan dan pelanggaran. Paradigma peneiitian ini adalah kualitatif.Metode yang digunakan adalah analisis isi pragmatik dan prosedur induktif. Data penelitian berupa kutipan-kutipan dialog dalam diskusi internet yang mengandung realisasi prinsip prinsip kesantunan. Data tersebut diperoleh dari rekaman tertulis dialog dalam diskusi internet di tiga grup diskusi Hindu Indonesia. I Iasil penelitian ini menunjukkan bahwa secara umumprinsip kesantunan cendcrung dipatuhi. Ini berarti mereka yang terlibat dalam diskusi internet di tiga grup diskusi Hindu Indonesia secara umum dikategorikan santun dalam berbahasa.
\end{abstract}

Kata Kunci: Realisasi, prinsip kesantunan, diskusi internet

\begin{abstract}
This study aims to gain a deep understanding of the politeness principlereali^ation in the internet discussion of three Indonesian Hindu groups. Realisation of politeness principle consist of compliance and qffense.This research paradigm is qualitative. The method used is pragmatics content analysis and inductive procedure. The data of this research is in the form of dialogue excerpts in internet discussions containing the realisation of politeness principles. The data obtained from the written dialogue record on the three Indonesian Hindu discussion groups in internet. The results oft his study indicatethatin generalthe principle of politeness tends to be obeyedThese means they are involved in internet discussions on the three discussion groups generally categorized Hindu Indonesia polite in speaking.
\end{abstract}

Keywords: Realisation, politeness principles, internet discussion

\section{PENDAHULUAN}

Penerapan prinsip kesantunan dalam berbahasadi masyarakat sungguh penting. Melalui penerapan prinsip ini, pemakai bahasa bisa menebarkan kesejukan di tengah gejolak masyarakat akibat perbedaan prinsip dan keyakinan hidup. Akan tetapi,penerapan tersebut tampaknya belum optimal, khususnya dalam diskusi internet.

Bahasa dalam diskusi internet tidak terlepas dari konteks budaya dan latar sosial. Oleh karena itu, seorang pengguna bahasa secara sosial tidak bisa bersikap seenaknya dalam berbahasa tanpa memperhatikan konteks budaya dan latar sosialnya (Schiffrin, 1994:626-627). Selaras dengan hal ini, pentingnya memahami konteks juga telah dikemukakan oleh Gumperz pada topik Context and CommunicationiYLtidrmns dkk., 2002:82-83), dan juga penjelasan oleh Hardey (1999:34) tentang pentingnya mempertimbangkan konteks sosial dalam berkomunikasi. Sehubungan dengan itu, Kramsch(1998:56) juga membahas tentang perlunya mempertimbangkan dua jenis konteks, yakni konteks situasi dan konteks budaya. Hal ini sejalan dengan apa yang dikemukakan oleh Achmad H.P. (1994:75) bahwa wacana sebagai rekaman bahasa digunakan baik 
dalam konteks sosial maupun konteks budaya. Untuk memahami wacana diperlukan pemahaman akan konteks sosial dan konteks budaya tersebut.

Berdasarkan beberapa pendapat tentang pentingnya pemahaman terhadap konteks tetsebut, maka dapat dikatakan bahwa pemahaman terhadap konteks menjadi prasyaratutama komunikasi. Pengguna bahasa yang tidak mengindahkan konteks dalam komunikasinya adalah pengguna bahasa yang gagal dalam berkomunikasi.

Hubungan antara konteks dan kesantunan adalah bahwa pemahaman terhadap konteks komunikasi membantu seseorang untuk bisa memilih bahasa santun yang cocok untuk diutarakan. Selain itu, dengan mengerti konteks, seseorang juga akan mengerti apakah bahasa yang digunakan mitra tuturnya santun atau tidak. Sebuah tuturan bisa saja disebut santun dalam suatu konteks, dan bisa dianggap tidak santun dalam konteks lain.

Dengan memahami konteks, seseorang juga memahami dan mampu menerapkan kesantunan. Dengan menerapkan kesantunan maka hubungan peserta komunikasi akan menjadi harmonis. Hal ini sejalan dengan pendapat Wardaugh(1 986:233) bahwa satu fungsi komunikasi yang terpenting seperti yang digariskan oleh teori etoografi dan etnometodologi adalah untuk menjaga keberlangsungan hubungan antara peserta komunikasi. Bahasa yang digunakan sebagai alatnya berisi kaidah-kaidah yang mengatur bagaimana seharusnya seseorang berkomunikasi agar relasi interpersonal para pemakainya terpelihara.

Jadi, sehubungan dengan satu fungsi komunikasi tersebut, maka ada satu prinsip yang hams dilaksanakan, yakni prinsip kesantunan. Demikianlah pentingnya realisasi kesantunan dalam berkomunikasi. Akan tetapi, berdasarkan studi pendahuluan di Forum Diskusi Jaringan Hindu Nusantara pada tanggal 15 Maret 2011 dan di grup diskusi Cakrawayupada tanggal 30 April 2011,teramati banyak penggunaan bahasa yang tidak mempedulikan prinsip kesantunan ini.

Berdasarkan uraian tersebut, maka penggunaan bahasa di internet, khususnya dalam grup diskusi, layak untuk diteliti. Penelitian ini mengkaji realisasi kesantunan dalam diskusi internet di tiga grup diskusi Hindu Indonesia, yakni Grup Bhakti Manama Wedanta, Forum Diskusi Jaringan Hindu Nusantara, dan Cakrawayu. Realisasi yang dimaksud adalah pematuhan dan pelanggaran prinsip tersebut. Teori utama yang diacu dalam penelitian ini adalah teori prinsip kesantunan oleh Leech.

Alasan dilakukannya penelitian hanya di tiga grup diskusi tersebut adalah karena di antara puluhan grup diskusi Hindu Indonesia, hanya tiga grup tersebut yang besar dan populer. Ketiga grup tersebut dikelola oleh yayasan, sehingga dapat dipercaya visi dan misinya. Masing-masing grup merniliki lebih dari 2.000 anggota.

Selanjutnya, pertimbangan dilakukan penelitian di grup yang berbasis Hindu adalah karena ada beberapa sistem nilai budaya Hindu yang ternyata relevan dengan prinsip kesantunan. Dalam budaya Hindu ada abimsa atautidak melakukan kekerasan (Prabhupada, 1986:541).Artinya,seseorang jangan menyakiti atau merugikan orang lain termasuk dalam hal berbahasa. Hal ini selaras dengan prinsip kesantunan.

Lebih lanjut, di Hindu juga ada ajaran tattvam asi yang artinya aku dan kamu adalah hamba Tuhan (Krishna, 2008:11). Jadi, ini mengajarkan tentang kesamaan sebagai hamba Tuhan. Karena sama-sama hamba Tuhan, maka sepatutnya saling menghormati dan bersimpati.

Dalam budaya Hindu Indonesia ada Tri Hita Karana yang artinya tiga penyebab kebahagiaan. Ketiga penyebab yang dimaksud terimplementasi dalam tiga harmoni, yakni: (1) harmoni hubungan antara manusia dengan Tuhan, (2) harmoni hubungan antara manusia dengan sesama manusia, dan (3) harmoni hubungan antara manusia dan alam atau lingkungannya (Jaman, 2007:20). Kalau merujuk pada harmoni poin (2), dapat dipahami bahwa harmoni tersebut membutuhkan komunikasi yang juga harmoni. Dengan kata lain, komunikasi yang harmoni adalah komunikasi yang santun.

Kemudian ada juga Tri Kaya Parisudha yang artinya tiga hal yang hams dijaga dan disucikan, yakni: pikiran, bahasa, dan perbuatan (Suhardana, 2006:29). Seseorang dikatakan berbahasa yang terjaga dan suci apabila tidak mencaci maki orang 
lain, tidak berkata-kata kasar, tidak memfitnah, dan tidak ingkar janji. Hal ini sangat sesuai dengan Prinsip kesantunan.

Selain itu, dalam karya yang berjudul Sri Sri Siksastakayang dihimpun olehAcyutananda dan Jayasacinandana (1972:20)terdapat ajaran yang juga sangat mendasar, yakni kerendahan hati (trnad api sunicena), lebih toleran dari sebatang pohon dan bebas dari rasa bangga yang palsu (taror api sabisnuna), dan tidak mengharapkan penghormatan tetapi bersedia memberikan segala penghormatan kepada orang lain (amanina manadena). Tiga poin dari ajaran dalam Sri Sri Siksastakasm sesuai dengan prinsip kesantunan.

Terakhir, dalam Hindu juga ada CaturParamita yang artinya empat perbuatan luhur. Kempat perbuatan itu adalah maitri atau bersahabat, karuna atau cinta kasih, mudhita atau bersimpati, dan upeksa atau toleransi (Suhardana, 2006:48-49). Hal ini sejalan dengan prinsip kesantunan, khususnya mudhita yang relevan dengan maksim kesimpatian.

Pertimbangan lain, ada anggapan umum bahwa orang Bali yang nota bene merupakan mayoritas penganut Hindu Indonesia memiliki karakter halus, ramah, suka bekerja sama, dan santun bahasanya. Setidaknya, kesan itu yang ditangkap dan diungkapkan oleh orang-orangyang pernah berwisata ke Bali. Akan tetapi, berdasarkan studi pendahuluan di tiga grup diskusi Hindu Indonesia tersebut, teramati ketidaksesuaian antara anggapan umum tersebut dengan realitas penggunaan bahasa, khususnya dalam berdiskusi. Sudah banyak teramati penggunaan bahasa yang tidak mempedulikan prinsip kesantunan.

Permasalahan umum penelitian ini adalah: bagaimanakah realisasi prinsip kesantunan dalam diskusi internet di tiga grup diskusi Hindu Indonesia? Permasalahan umum ini kemudian dirinci sebagai berikut. (a) Bagaimanakah realisasi maksim kebijaksanaan dalam diskusi internet di tiga grup diskusi Hindu Indonesia? (b) Bagaimanakah realisasi maksim penerimaan dalam diskusi internet di tiga grup diskusi Hindu Indonesia? (c) Bagaimanakah realisasi maksim kemurahan dalam diskusi internet di tiga grup diskusi Hindu Indonesia? (d) Bagaimanakah realisasi maksim kecocokan dalam diskusi internet di tiga grup diskusi Hindu Indonesia? (e)
Bagaimanakah realisasi maksim kerendahan hati dalam diskusi internet di tiga grup diskusi Hindu Indonesia? (f) Bagaimanakah realisasi maksim kesimpatian dalam diskusi internet di tiga grup diskusi Hindu Indonesia?

Ada sejumlah pakar yang telah menulis mengenai teori kesantunan berbahasa. Diantaranya adalah Lakoff, Fraser, Brown dan Levinson, dan Leech (Eelen, 2001:2-13).

LakolT sebagaimana dikutip oleh Rahardi (2005:70) berpendapat bahwa supaya tuturan menjadi santun, ada tiga hal yang harus perhatikan, yakni: (1) formalitas (formality) jangan memaksa, (2) ketidaktegasan (hesitancy) berarti buatlah supaya mitra tutur dapat menentukan pilihan,dan (3) persamaan (equality) berarti bertindaklah seolah-olah Anda dan mitra tutur Anda sama.

Dengan kata lain dapat clinyatakan bahwa penutur hendaknya tidak memaksa, karena secara alarm, setiap orang tidak menyukai paksaan. Selanjutnya penutur memberi pilihan kepada mitra tutur, karena dengan banyaknya pilihan untuk menjawab atau bertindak, mitra tutur akan menjadi nyaman. Begitu juga penutur hendaknya berupaya "sepaham" dengan mitra tutur. Dengan sepaham, mitra tutur juga akan merasa nyaman.

Fraser membedakan antara kesantunan (politeness) dengan penghormatan (deference). Menurut Fraser, kesantunan adalah properti tuturan.Kesantunan berarti penutur tidak berlebihan dalam mengambil hak-haknya atau tidak mengingkari dalam memenuhi kewajibannya. Sedangkan penghormatan adalah bagian dari aktivitas yang berfungsi sebagai sarana simbolis untuk menyatakan penghargaan secara reguler. Kalau seseorang tidak menggunakan "bahasa pasaran" kepada seorang pejabat di kantornya, maka orang itu berartihormat kepada pejabat yang menjadi mitra tuturnya. Akan tetapi, berperilaku hormat belum tentu berperilaku santun.

Yang dimaksud dengan hak di sini adalah sesuatu yang menjadi milik penutur atau mitra tutur; dan yang dimaksud dengan kewajiban adalah keharusan yang harus dilakukan oleh peserta pertuturan. Di antara hak-hak penutur dalam suatu proses pertuturan adalah hak untuk 
bertanya, misalnya. Namun, hak ini bukanlah tanpa batas (Gunarwan, 2007:188).

Jadi dapat disimpulkan bahwa dalam berkomunikasi, meskipun penutur memiliki hak untuk bertutur, tetapi ia wajib untuk membuat mitra tutur nyaman. Begitu juga mitra tutur mempunyai kewaijiban untuk mendengarkan, selain hak untuk bertutur ketika gilirannya tiba.

Brown dan Levinson (1996:61-62) mengemukakan kesantunan nosi muka (face). Muka itu ada dua segi yaitu muka negatifdan muka positif. Muka negatif itu mengacu pada citra diri setiap orang yang berkeinginan agar ia dihargai dengan jalan membiarkannya bebas melakukan tindakan atau membiarkannya bebas dari keharusan mengerjakan sesuatu. Selanjutnya, yang dimaksud dengan muka positif adalah sebaliknya, yakni mengacu pada citra diri setiap orang berkeinginan agar apa yang dilakukannya, apa yang dimilikinya atau apa yang merupakan nilai-nilai yang ia yakini, sebagai akibat dari apa yang dilakukan atau dirmlikinya itu, diakui orang lain sebagai suatu hal yang baik, yang menyenangkan, yang patut dihargai, dan seterusnya.

Leech (1983:132) mengajukan teori kesantunan berdasarkan prinsip kesantunan (politenessprincipies), yang dijabarkan menjadi enam maksim. Keenam maksim itu yakni: (1) kebijaksanaan (tact), (2) penerimaan (generosity), (3) kemurahan (approbation), (4) kerendahan hati (modesty), (5) kesetujuan/ kecocokan (agrement), dan (5) kesimpatian (sympatby).

Maksim merupakan kaidah kebahasaan di dalam interaksi lingual; kaidah-kaidah yang mengatur tindakan, penggunaan bahasa, dan interpretasi-interpretasinya terhadap tindakan dan ucapan lawan tutur. Keenam maksim dari prinsip kesantunantersebut menganjurkan agar kita mengungkapkan keyakinan-keyakinan dengan sopan dan menghindari ujaran yang tidak sopan.

Prinsip kesantunan dikatakan oleh Grundy (2000:145) sebagai suatu fenomena. Dia mengutip pernyataan Lakoff, Leech, dan Brown \& Levinson, bahwa prinsip kesantunan telah dianggap memiliki pengaruh yang luas dalam hal penggunaan bahasa, menjadi penentu utama perilaku berbahasa, dan bersifat universal.

Penelitian ini hanya mengkaji realisasi prinsip kesantunan yang dikemukakan oleh Leech.
Realisasi prinsip yang climaksudkan adalah pelaksanaan secara nyata prinsip prinsip tersebut, baik pematuhan maupun pelanggarannya. Pertimbangan chpilihnya prinsip tersebut adalah karena apa yang dikemukakan Lakoff bahwa sebuah tuturan dikatakan santun apabila ia tidak terdengar memaksa atau angkuh, tuturan itu memberi pilihan kepada mitra tutur, dan mitra tutur merasa tenang, ini sudah tercakup dalam maksim-maksim kesantunan oleh Leech. Begitu juga halnya dengan apa yang dikemukakan Fraser yang membedakan antara kesantunan dan penghormatan serta penekanan pada hak dan kewajiban; Brown \& Levinson dengan teori muka positif dan negatif juga sudah tercakup dalam maksim-maksim Leech. Selain itu, apa yang dikemukakan Fraser dan Brown \& Levinson adalah merupakan strategi, sedangkan apa yang diteliti (dalam penelitian ini) dikaji dengan teori maksim.

Realisasi prinsip tersebut mencakup pematuhan dan pelanggaran. Untuk memudahkan analisis, dibuatkan kriteria yang diadaptasi dari Principles of Pragmatics oleh Geoffrey Leech (1983:132) seperti di bawah ini.

Tabel 1. Kriteria Pematuhan Prinsip kesantunan

\begin{tabular}{|c|l|l|}
\hline No & \multicolumn{1}{|c|}{ Maksim } & \multicolumn{1}{|c|}{ Kriteria Tuturan } \\
\hline 1 & Kebijaksanaan & Untungkan orang lain \\
\hline 2 & Penerimaan & Rugikan diri sendiri \\
\hline 3 & Kemurahan & Hormati orang lain \\
\hline 4 & Kerendahan Hati & Rendahkan diri sendiri \\
\hline 5 & Kecocokan & $\begin{array}{l}\text { Setujui pendapat/ide } \\
\text { orang lain }\end{array}$ \\
\hline 6 & Kesimpatian & $\begin{array}{l}\text { Simpati kepada orang } \\
\text { lain }\end{array}$ \\
\hline
\end{tabular}

Tujuan utama penelitian ini adalahuntuk memperoleh pemahaman yang mendalam tentang realisasi prinsip kesantunan dalam diskusi internet di tiga grup diskusi Hindu Indonesia. Realisasi tersebut yakni: (a) realisasi maksim kebijaksanaan, (b) realisasi maksim penerimaan, (c) realisasi maksim kemurahan, (d) realisasi maksim kerendahan had, (e) realisasi maksim kecocokan dan (f) realisasi maksim kesimpatian. 


\section{METODE}

Paradigma penelitian ini adalah kualitatif. Metode yang digunakan adalah metode analisis isi pragmatik dan prosedur induktif. Model pengategorian yang dijadikan dasar adalah model Mayring (2011:2).

Data yang diperoleh dianalisis kemudian dikelompokkan ke dalam kategori-kategori yang ditetapkan sebelumnya. Aspek-aspek interpretasi teks mengikuti pertanyaan penelitian dimasukkan ke dalam kategori-kategori. Kategori-kategori direvisi dan diverinkasi bersamaan dengan jalannya proses analisis.

Untuk mendapatkan data mengenai realisasiprinsip kesantunan berbahasa tersebut, peneliti berperan sebagai instrumen pengumpul data dengan menggunakan alat bantu berupa perangkat netbook, perangkat internet dan printer. Netbook dan perangkat internet digunakan untuk online ke tiga grup diskusi, printer digunakan untuk mencetak dokumen (hasil diskusi). Pemeriksaan keabsahan data penelitian ini menggunakan:(1) kredibilitas, (2) transferabilitas (keteralihan), (3) auditabilitas (dependabilitas), dan (4) konftrmabilitas (dapat dikonfirmasi).
Analisis data penelitian ini dilakukan selama dan setelah pengumpulan data berlangsung. Selama pengumpulan data berlangsung,dilakukan kegiatan mereduksi data, selanjutnya membuat ringkasan, mengkode, memilih data, meringkas, dan membuat kesimpulan sementara.Adapun analisis setelah pengumpulandata mengacu pada kerangka kerja anaHsis,yaknipenarikan kesimpulan hasil temuan yang berupa hasil dokumentasi. Adapun langkah-langkah analisis data adalah: (1) pengumpulan data,(2) reduksi data, (3) penyajian data, dan (4) menarik kesimpulan dan verifikasi.

\section{HASIL DAN PEMBAHASAN}

Temuan penelitian yang diuraikan pada bagian ini adalah realisasi prinsip kesantunan dalam diskusi internet di tiga grup diskusi Hindu Indonesia. Realisasi ini mencakup enam maksim, yakni maksim kebijaksanaan, maksim penerimaan, maksim kemurahan, maksim kerendahan hati, maksim kecocokan, dan maksim kesimpatian. Masing-masing maksim tersebut dideskripsikan pematuhan dan pelanggarannya. Temuan ini disajikan dalam tabel di bawah ini.

Tabel 2. Temuan Realisasi Prinsip kesantunan

\begin{tabular}{|c|l|l|c|c|c|c|c|c|c|c|c|c|c|c|c|c|c|}
\hline \multirow{2}{*}{ No } & \multirow{2}{*}{ Grup } & \multirow{2}{*}{ Topik Diskusi } & \multicolumn{2}{|c|}{ Keb } & \multicolumn{2}{|c|}{ Pen } & \multicolumn{2}{|c|}{ Kem } & \multicolumn{3}{|c|}{ Ker } & \multicolumn{2}{|c|}{ Kec } & \multicolumn{2}{|c|}{ Kes } & \multicolumn{2}{|c|}{ Ket. } \\
\hline & & & + & - & + & - & + & - & + & - & + & - & + & - & + & - \\
\hline 1 & BMW & Terjemahan. BG & 19 & 12 & 22 & 9 & 20 & 11 & 22 & 9 & 19 & 12 & 27 & 4 & $\sqrt{ }$ & \\
\hline 2 & BMW & Popularitas. HK & 7 & 7 & 6 & 8 & 6 & 8 & 6 & 8 & 6 & 8 & 7 & 7 & & $\sqrt{ }$ \\
\hline 3 & BMW & Vaikunta Loka & 13 & 11 & 13 & 11 & 12 & 12 & 10 & 14 & 11 & 13 & 11 & 13 & & $\sqrt{ }$ \\
\hline 4 & BMW & Susila Hindu & 6 & 7 & 6 & 7 & 6 & 7 & 5 & 8 & 6 & 7 & 6 & 7 & & $\sqrt{ }$ \\
\hline 5 & BMW & Budaya HK & 8 & 11 & 2 & 17 & 8 & 11 & 6 & 13 & 5 & 14 & 5 & 14 & & $\sqrt{ }$ \\
\hline 6 & BMW & Kekej.di Lamp & 8 & 12 & 8 & 12 & 10 & 10 & 5 & 15 & 7 & 13 & 9 & 11 & & $\sqrt{ }$ \\
\hline 7 & BMW & Doa utk Balinur. & 7 & - & 7 & - & 7 & - & 7 & - & 6 & 1 & 7 & - & $\sqrt{ }$ & \\
\hline 8 & BMW & Tele. Kasus Lamp & 7 & 3 & 7 & 3 & 7 & 3 & 6 & 4 & 7 & 3 & 6 & 4 & $\sqrt{ }$ & \\
\hline 9 & BMW & Huk. Karmaphala & 13 & 19 & 12 & 10 & 13 & 19 & 10 & 12 & 15 & 7 & 12 & 10 & $\sqrt{ }$ & \\
\hline 10 & BMW & Leak Sanur & 21 & 5 & 19 & 7 & 20 & 6 & 14 & 12 & 20 & 6 & 14 & 12 & $\sqrt{ }$ & \\
\hline 11 & CPB & Feno. P. Paradev & 9 & 2 & 9 & 2 & 9 & 2 & 9 & 2 & 9 & 2 & 9 & 2 & $\sqrt{ }$ & $\sqrt{ }$ \\
\hline 12 & CPB & Kremasi & 4 & 6 & 2 & 8 & 4 & 6 & 4 & 6 & 3 & 7 & 4 & 6 & & $\sqrt{ }$ \\
\hline 13 & CPB & Srila Prabhupada & 4 & 6 & 3 & 7 & 4 & 6 & 3 & 7 & 3 & 7 & 3 & 7 & & $\sqrt{ }$ \\
\hline 14 & CPB & Radhastami & 3 & 6 & 3 & 6 & 3 & 6 & 3 & 6 & 3 & 6 & 3 & 6 & & $\sqrt{ }$ \\
\hline 15 & CPB & Syair Hare Krsna & 3 & 7 & 3 & 7 & 3 & 7 & 5 & 5 & 4 & 6 & 5 & 5 & $\sqrt{ }$ & \\
\hline 16 & CPB & Opsi Damai Lamp & 11 & 5 & 9 & 7 & 13 & 3 & 7 & 9 & 10 & 6 & 9 & 7 & $\sqrt{ }$ & \\
\hline 17 & CPB & Demonstrasi & 20 & 1 & 19 & 2 & 20 & 1 & 19 & 2 & 20 & 1 & 20 & 1 & $\sqrt{ }$ & \\
\hline 18 & CPB & Lamp. Membara & 6 & 1 & 6 & 1 & 6 & 1 & 4 & 3 & 4 & 3 & 4 & 3 & $\sqrt{ }$ & \\
\hline 19 & CPB & Arya Weda & 11 & 4 & 12 & 3 & 12 & 3 & 12 & 3 & 12 & 3 & 12 & 3 & $\sqrt{ }$ & \\
\hline
\end{tabular}




\begin{tabular}{|c|c|c|c|c|c|c|c|c|c|c|c|c|c|c|c|c|}
\hline \multirow{2}{*}{ No } & \multirow{2}{*}{ Grup } & \multirow{2}{*}{ Topik Diskusi } & \multicolumn{2}{|c|}{ Keb } & \multicolumn{2}{|c|}{ Pen } & \multicolumn{2}{|c|}{ Kem } & \multicolumn{2}{|c|}{ Ker } & \multicolumn{2}{|c|}{ Kec } & \multicolumn{2}{|c|}{ Kes } & \multicolumn{2}{|c|}{ Ket. } \\
\hline & & & + & - & + & - & + & - & + & - & + & - & + & - & + & - \\
\hline 20 & $\mathrm{CPB}$ & Kerusuhan Baru & 18 & 3 & 10 & 11 & 18 & 3 & 11 & 10 & 16 & 5 & 8 & 13 & $\sqrt{ }$ & \\
\hline 21 & $\mathrm{JHN}$ & Komentar JK & 9 & 9 & 7 & 11 & 13 & 5 & 7 & 11 & 10 & 8 & 8 & 10 & & $\sqrt{ }$ \\
\hline 22 & $\mathrm{JHN}$ & Demo. utk. Lamp. & 11 & 8 & 9 & 10 & 15 & 4 & 11 & 8 & 14 & 5 & 14 & 5 & $\sqrt{ }$ & \\
\hline 23 & JHN & Balinu. Diserang & 18 & 5 & 17 & 6 & 20 & 3 & 17 & 6 & 20 & 3 & 17 & 6 & $\sqrt{ }$ & \\
\hline 24 & JHN & Toleransi & 8 & 8 & 10 & 6 & 13 & 3 & 6 & 10 & 12 & 4 & 12 & 4 & $\sqrt{ }$ & \\
\hline 25 & $\mathrm{JHN}$ & Pen. Kerusuhan & 10 & 12 & 4 & 18 & 5 & 17 & 6 & 16 & 9 & 13 & 10 & 12 & & $\sqrt{ }$ \\
\hline 26 & JHN & Kailasha & 6 & 4 & 5 & 5 & 6 & 4 & 7 & 3 & 3 & 7 & 6 & 4 & $\sqrt{ }$ & \\
\hline 27 & $\mathrm{JHN}$ & $\begin{array}{l}\text { Upacara. Kem. } \\
\text { HK }\end{array}$ & 6 & 1 & 4 & 3 & 5 & 2 & 2 & 5 & 3 & 4 & 2 & 5 & $\sqrt{ }$ & \\
\hline 28 & JHN & Bhajan & 10 & - & 10 & - & 10 & - & 10 & - & 10 & - & 10 & - & $\sqrt{ }$ & \\
\hline 29 & JHN & Peresmian Gereja & 4 & 6 & 3 & 7 & 4 & 6 & 5, & 5 & 5 & 5 & 5 & 5 & & $\sqrt{ }$ \\
\hline 30 & $\mathrm{JHN}$ & Salam Hindu & 5 & 3 & 4 & 4 & 7 & 1 & 6 & 2 & 5 & 3 & 6 & 2 & $\sqrt{ }$ & \\
\hline & & Jumlah & 285 & 174 & 251 & 208 & 289 & 170 & 245 & 214 & 277 & 182 & 271 & 188 & 18 & 12 \\
\hline
\end{tabular}

\section{Keterangan Tabel}

BMW $=$ Grup Diskusi Bhakti Manawa Wedanta
CPB $=$ Grup Diskusi Cakrawayu Peduli Bali
JHN $=$ Grup Diskusi Jaringan Hindu Nusantara
Keb $=$ Maksim Kebijaksanaan
Pen $=$ Maksim Penerimaan
Kem $=$ Maksim Kemurahan

$\begin{array}{ll}\text { Ker } & =\text { Maksim Kerendahan Hati } \\ \text { Kec } & =\text { Maksim Kecocokan } \\ \text { Kes } & =\text { Maksim Kesimpatian } \\ + & =\text { Pematuhan } \\ - & =\text { Pelanggaran }\end{array}$

Berdasarkan tabel di depan, terlihat bahwa secara umum prinsip kesantunan cenderung dipatuhi. Dari total 2754 analisis, sebanyak 1618 mematuhi dan 1136 melanggar. Jika dilihat dari analisis setiap topik diskusi, maka dari 30 topik diskusi, sebanyak 18 topik yang diskusinya cenderung mematuhi prinsip kesantunan $(+)$ dan hanya 12 topik yang cenderung melanggar (-).

Dari 18 topik yang diskusinya cenderung mematuhi prinsip kesantuanan tersebut, ada2 topik diskusi yang hasil analisis maksimnya tidak mengandung pelanggaran. Topik itu adalah Doa untuk Balinuraga dan Bhajan. Pada topik Doa untuk Balinuragahanja pada maksim kecocokan terdapat pelanggaran. Sedangkan untuk topik Bhajan tidak ada pelanggaran maksimnya.Tabel tersebut juga menunjukkan bahwa berdasarkan hasil analisis terhadap realisasi enam maksim dalam prinsip kesantunan, tidak ada maksim yang cenderung diknggar.

Pembahasan tentang realisasi prinsip kesantunandalam diskusi internet di tiga grup diskusi Hindu Indonesia dilakukan setiap maksim sebagai berikut.

\section{a. Realisasi Maksim Kebijaksanaan}

Pematuhan maksim kebijaksanaan berjumlah 285 dan pelanggarannya 174Leech (1983:132) menyatakan bahwa maksim ini mengharuskan setiap partisipan untuk meminimalkan kerugian orang lain, atau memaksimalkan keuntungan bagi orang lain. Jika dilihat berdasarkan kecenderungan, maka dapat dinyatakan bahwa maksim kebijaksanaan cenderung dipatuhi. Ini dapat dimaknai bahwa penutur dalam diskusi internet di tiga grup diskusi Hindu Indonesia secara umum bijaksana dalam berbahasa. Dengan kata lain, secara umum penutur cenderung menguntungkan mitra tuturnya. Jika dikaitkan dengan sistem nilai dalam budaya Hindu Indonesia, maka temuan tersebut dapat dimaknai bahwa pelaku diskusi sudah berperilaku abimsakatena. sudah berdiskusi tanpa kekerasan bahasa dengan begitu mereka tidak merugikan mitra tuturnya. Kemudian bisa juga dikatakan secara umum telah mengamalkan Tri Hita Karana, khususnya menyangkut harmoni hubungan antara penutur dan mitra tutur. Selanjutnya, dapat pula 
dikatakan bahwa secara umum pelaku diskusi telah berperilaku sesuai dengan Tri Kaya Paristidha, khususnya tentang berbahasa yang terjaga dan suci. Dengan berbahasa seperti itu, maka mitra tutur tidak akan dirugikan.

\section{b. Realisasi Maksim Penerimaan}

Pematuhan maksim penerimafln berjumlah 251 dan pelanggarannya 208.Leech (1983:132) menyatakan bahwa maksim ini mewajibkan setiap partisipan untuk memaksimalkan kerugian diri sendiri dan meminimalkan keuntungan diri sendiri. Jika dilihat berdasarkan kecenderungan, maka dapat dinyatakan bahwa maksim penerimaan cenderung dipatuhi. Ini dapat dimaknai bahwa penutur dalam diskusi internet di tiga grup diskusi Hindu Indonesia secara umum mau untuk merugikan diri sendiri demi mitra tuturnya. Dengan kata lain, penutur menjaga supaya orang lain senang dan merasa diuntungkan. Hal ini sejalan dengan apa yang dikatakan oleh Watts (2003:39) bahwa kesantunan adalah kemampuan untuk menyenangkan orang lain(melalui pemakaian bahasaseseorang). Jika dikaitkan dengan sistem nilai budaya Hindu Indonesia, maka temuan tersebut dapat dimaknai bahwa peserta diskusi secara umum mempraktikkan

Tri Hita Karana, khususnya tentang harmoni hubungan antara penutur dan mitra tutur. Selain itu, temuan tersebut juga mencerminkan bahwa secara umum sesuai dengan Sri Sri Siksastaka, khususnya tentang kerendahan hati \{trnad api sunicena) dan tidak mengharapkanpenghormatan, tetapi bersedia memberi segala hormat kepada orang hm(amanina manadena). Kerendahan hati berarti bersedia merugikan diri sendiri di hadapan mitra tutur. Ini berkaitan juga dengan tidak mencari penghormatan dari orang lain. Dengan tidak mencari penghormatan, maka seseorang telah berupaya merugikan clirinya sendiri.

\section{c. Realisasi Maksim Kemurahan}

Pematuhan maksim kemurahan berjumlah 289, pelanggarannya 170.Leech (1983:132) menyatakan bahwa maksim ini menganjurkan dua hal yaitu kecamlah orang lain sesedikit mungkin dan pujilah orang kin sebanyak mungkin. Jika dilihat berdasarkan kecenderungan, maka dapat dinyatakan bahwa maksim kemurahan cenderung dipatuhi. Ini dapat dimaknai bahwa penutur dalam diskusi internet di tiga grup diskusi Hindu Indonesia secara umum tidak suka mengecam atau mereka bersedia memuji mitra tuturnya. Dengan kata lain, penutur bersedia menghormati mitra tuturnya. Tampaknya para penutur dalam konteks tersebut secara umum masih mengamalkan sistem nilai budaya Hindu, yakni abimsa yang artinya tidak menyakiti orang lain, yang di dalamnya juga termasuk tidak mengecam orang lain. Juga tampak mengamalkan tattuam asi yang mengajarkan tentang kesamaan sebagai hamba Tuhan. Karena sama-sama hamba Tuhan, maka sepatutnya saling menghormati. Selain itu, ajaran Trikaya Parisudha yang salah satu ajarannya menganjurkan orang untuk menyucikan kata-kata atau ujarannya, secara umum juga masih tampak terealisasi.

\section{d. Realisasi Maksim Kerendahan Hati}

Pematuhan maksim kerendahan hati berjumlah 245 dan peknggarannya 214.Menurut Leech (1983:132), maksim kerendahan hati menuntut setiap partisipan untuk memaksimalkan ketidakhormatan pada diri sendiri atau meminimalkan rasa hormat kepada diri sendiri. Jika dilihat berdasarkan kecenderungan, maka dapat dinyatakan bahwa maksim kerendahan hati cenderung dipatuhi. Ini dapat dimaknai bahwa penutur dalam diskusi internet di tiga grup diskusi Hindu Indonesia secara umum rendah hati. Mereka bersedia merendahkan diri sendiri di hadapan mitra tuturnya. Dengan kata lain, mereka tidak sombong. Jika dikaitkan dengan sistem nilai budaya Hindu Indonesia, maka temuan tersebut mencerminkan bahwa ajaran Sri Sri Siksastaka,yaknitrfiad api sunicena (kerendahan h.ati),taror api sahisnunaQebih toleran dari sebatang pohon, bebas dari rasa bangga yang palsu), dan amanina manadenaltidak mengharapkan penghormatan tetapi bersedia memberi segala penghormatan kepada orang lain), secara umum masih diamalkan oleh para penutur.

\section{e. Realisasi Maksim Kecocokaan \\ Pematuhan maksim kecocokan berjumlah 277 dan pelanggarannya 182.Leech (1983:132)}


menyatakan bahwa maksim kecocokan menggariskan setiap partisipan untuk memaksimalkan kecocokan di antara mereka, dan meminimalkan ketidakcocokan di antara mereka. Jika dilihat berdasarkan kecenderungan, maka dapat dinyatakan bahwa maksim kecocokan cenderung dipatuhi. Ini dapat dimaknai bahwa penutur dalam diskusi internet di tiga grup diskusi Hindu Indonesia secara umum cocok dengan mitra tuturnya. Dengan kata lain, cocok berarti tidak berdebat. Jika dikaitkan dengan sistem nilai budaya Hindu, maka temuan tersebut dapat dimaknai bahwa penutur secara umum berperilaku sesuai dengan Catur Paramita, khususnya poin keempat, yakni upeksa (toleransi). Dengan menjaga kecocokan, maka penutur bisa disebut mampu mentoleransi perbedaan ide.

\section{f. Realisasi Maksim Kesimpatian}

Pematuhan maksim kesimpatian ini berjumlah 271,pelanggarannya 188.Menurut

Leech (1983:132), maksim kesimpatian ini mengharuskan setiap partisipan untuk memaksimalkan rasa simpati dan meminimalkan rasa antipati kepada mitra tuturnya.Jika dilihat berdasarkan kecenderungan, maka dapat dinyatakan bahwa maksim kesimpatian cenderung dipatuhi. Ini dapat dimaknai bahwa para penutur dalam diskusi internet di tiga grup diskusi Hindu Indonesia secara umum bersimpati dengan mitra tuturnya. Jika dikaitkan dengan sistem nilai budaya Hindu Indonesia, maka temuan tersebut dapat dimaknai bahwa secara umum penutur sudah berperilaku tattvam asi, yakni sayang dan bersimpati kepada semua makluk. Selain itu juga tampak berperilaku sesuai dengan Catur Paramita, khususnya poin tiga, yakni mudhita (bersimpati).

Penelitian ini memiliki keterbatasan karena kajian realisasinya hanya pada prinsip kesantunan oleh Leech. Masih ada tiga jenis kesantunan yang lain yang tidak dikaji, yakni kesantunan yang dikemukakan oleh Brown dan Levinson, Fraser, dan Lakoff. Selain itu, ada hal yang menarik dan relevan dengan kesantunan ini, tetapi tidak dikaji dalam penelitian ini, yakni hubungan antara maksim-maksim dalam prinsip kesantunan oleh Leech dengan maksim-maksim dalam prinsip kerja sama oleh Grice.

\section{SIMPULAN}

Simpulan penelitian tentang realisasi prinsip kesantunan dalam diskusi internet di tiga grup diskusi Hindu Indonesia adalah secara umum prinsip kesantunan cenderung dipatuhi. Dari total 2754 analisis, sebanyak 1618 mematuhi dan 1136 melanggar. Ini berarti para penutur yang terlibat dalam diskusi internet di tiga grup diskusi Hindu Indonesia secara umum dikategorikan santun dalam berbahasa.

Rekomendasi penelitian ini dibagi menjadi dua, yakni rekomendasi teoretis dan rekomendasi praktis.Rekomendasi teoretis penelitian ini adalah perlu penambahan satu maksim lagi untuk prinsip kesantunan, yakni maksim toleransi.Selanjutnya, rekomendasi praktisdiperinci menjadi lima butir rekomendasi sebagai berikut: (a) Prinsip kesantunan direkomendasikan untuk dimasukan dalam kurikulum mata pelajaran bahasa Indonesia agar bisa diajarkan secara integratif sejak pendidikan dasar (SMP);(b) Kepada peneliti lain: direkomendasikan untuk meneliri tentang relasi pematuhan dan pelanggaran antara prinsip kesantunan dengan prinsip lain, yakni prinsip kerja sama. Selain itu, direkomendasikan juga untuk meneliti keterkaitan sistem nilai budaya (selain Hindu) dengan perilaku berbahasa yang terwujud dalam realisasi prinsip kesantunan; (c) Kepada dosen pengajar bahasa: hasil penelitian ini direkomendasikan untuk dijadikan bahan pemerkaya pengajaran pragmatik; (d) Kepada pengelola grup diskusi internet: hasil penelitian ini direkomendasikan untuk dijadikan masukan bagaimana memoderasi diskusi internet agar diskusi berjalan santun;dan (e) Kepada para pemuka agama Hindu: hasil penelitian direkomendasikan untuk dijadikan masukan dalam melakukan pembinaan kepada umat tentang pentingnya berbahasa yang santun karena ternyata hal itu relevan dengan sistem nilai budaya Hindu.

\section{DAFTAR PUSTAKA}

Achmad H.P. 1994. "Gaya Berpiktr, Latar Belakang Pendidikan, dan Kemampuan Menulis Mahasiswa IKIP Jakarta dalam Tiga 
Aspek Wacana: Keterpaduan, Keruntutan, dan Kelengkapan." Disertasi, IKIPJakarta.

Brown, Penelope dan Stephen C. Levinson. 1996. Politeness: Some Universals in Language Usage. New York: Cambridge University Press.

Helen, Gino. 2001. A Critique of Politeness Theories. Manchester: St. Jarome Pubkshing.

Eerdmans, Susan L., Carlo R. Prevignano, dan Paul J. Thibault. 2002. Language and Interaction: Discussion with John J. Gumper . Philadelpia: John Benjamins Pubkshing Company.

Grundy, Peter. 2000. Doing Pragmatics. New York: Oxford University Press. Gunarwan, Asim. 2007. Pragmatik: Teori dan Kajian

Nusantara. Jakarta: Universitas Atma Jaya. Hartley, Peter. 1999. Interpersonal Communication.

London: Roudedge. Jaman, I Gede. 2007.

Tri Hita Karana dalam Konsep

Hindu. Denpasar: Pustaka Bali Pos. Kramsch,

Claire. 1998. Language and Culture.

Oxford: Oxford University Press. Krishna,

Anand. 2008. Tri Hita Karana: Ancient

Balinese Wisdom for Neo Humans. Surabaya:

Anand Krishna Global Co-Operation.

Leech, Geoffrey. 1983. Principles of Pragmatics.

London: Longman. Mayring, Philipp.

Qualitative Content Analysis [28 paragraphs]. Forum Qualitative Sosjalforschung / Forum: Qualitative Social Research, /(2), Art. 20; http: / / www.qualitative research.net/index.

$\mathrm{php} / \mathrm{fqs} /$ article/view/1089/2385 (diakses 30 Oktober2011).

Prabhupada, Sri Srimad A.C. Bhakrivedanta Swami. 1986. Bhagavad-Gita As It Is. Mumbai: The Bhakrivedanta Book Trust

------, 2007. Pedoman Etika dan Pola Hidup Yaishnava. Denpasar: Sampradaya Kesadaran Krishna Indonesia.

Rahardi, R. Kunjana. 2005. Pragmatik: Kesantunan Imperatif Bahasa Indonesia. Jakarta: Erlangga.

Schiffrin, Deborah. 1994. Approaches to Discourse. Massachusetts: Blackwell Publisher.

Suhardana, K.M. 2006. Pengantar Etika dan Moralitas Hindu. Bahan Kajian untuk. Memperbaiki Tingkah Laku. Surabaya: Paramita.

Swami, Acyutananda dan Jayasacinandana Dasa. 1972. Lagu-Lagu Para Acarya Vaisnava. Jakarta: Pustaka Bhakrivedanta.

Wardaugh, Ronald. 1986. An Introduction of Sociolinguistics, Oxford: Basil Blackwell.

Watts, Richard J. 1986. Politeness. New York: Cambridge University Press.. 